Publisher: Blackwell Publishing

Citation: Australian Occupational Therapy Journal, Volume 54, Number 1, March 2007, pp. 22-32(11)

Original published version: $\underline{\text { http://dx.doi.org/10.1111/j.1440-1630.2006.00647.x }}$

\title{
Inpatients' Perspectives of Occupational Therapy in Acute Mental Health
}

Kee Hean Lim MSc, Dip COT, PG Cert in HE

Lecturer in Occupational Therapy

Directorate of Occupational Therapy

School of Health Sciences and Social Care

Mary Seacole Building, Brunel University

Uxbridge, Middlesex UB8 3PH

kee.hean.lim@brunel.ac.uk

Telephone 441895268744

Julia Morris MSc, Dip COT,

Head Occupational Therapist, South West London and St George's Mental Health NHS

Trust, Department of Occupational Therapy, Springfield University Hospital, 61 Glenburnie Road, London SW17 7DJ julia.morris@swlstg-tr.nhs.uk

Christine Craik MPhil, DMS, Dip COT, MCMI, ILTM

Director of Occupational Therapy

School of Health Sciences and Social Care

Mary Seacole Building, Brunel University

Uxbridge, Middlesex UB8 3PH

christine.craik@brunel.ac.uk

\begin{abstract}
Background

Research into service users' views of occupational therapy in acute mental health is

extremely limited. This collaborative study between South West London and St George's

Mental Health NHS Trust and Brunel University (UK) obtained inpatients’ perspectives of occupational therapy.
\end{abstract}




\section{Methods}

Service users and occupational therapists were involved in designing a self-report questionnaire and, following training, in recruiting participants and collecting data.

\section{Results}

Sixty-four (28.6\%) inpatients responded and most had met an occupational therapist who had explained the purpose of their intervention. The most frequent group interventions were arts and crafts, relaxation, community meetings, cookery, sports and gym, with the latter two rated as most beneficial. There was much less choice about individual goals and interventions. A highly significant and positive correlation was found between occupational therapy meeting the needs of individuals and it improving their daily functioning and quality of their admission.

\section{Conclusions}

Occupational therapists need to provide more individual interventions and more fully involve inpatients in deciding on individual goals. Group interventions, which are meaningful, relevant and with an occupational focus, are most beneficial. Further research examining the effectiveness of cookery and sport and gym and establishing the benefits of engaging in group and individual intervention on acute wards is warranted.

\section{Key Words}

Inpatients

Mental health

Occupational therapy

Patient participation 
Patient satisfaction 


\section{INTRODUCTION}

The provision and delivery of mental health services in many countries has fundamentally changed over the last decade, with a greater focus on care in the community, reconfiguration of acute services, emphasis on recovery and service user involvement (Lim, 2005; Lloyd, King \& Mass 1999b; Reberio, 2000). This shift in focus has implications for the provision of mental health services and further highlights the importance of ensuring quality and effective occupational therapy provision (Di Bona, 2004; Lloyd, Kanowski \& Maas, 1999a).

In the area of acute mental health, several concerns have been raised around the therapeutic benefits and quality of services provided to service users during a period when they are most vulnerable and unwell (Secker \& Harding, 2002). The Sainsbury Centre for Mental Health (1998) in their report on the state of acute mental health services in the United Kingdom (UK), highlighted this problem, citing poor quality of care, lack of therapeutic input, poor ward environment and the small but significant risk of violence to staff and patients as areas of concern. Crucially, it also emphasised the lack of service users being consulted and involved within their own treatment, as a primary area of concern.

Indeed, the improvised state of many acute inpatient services in the UK due to disparities in funding, staffing and therapeutic input, further constrains the delivery of standards and the provision of an effective mental health service (Department of Helath (DOH), 1999a, 2001). Recognition of the need to redress this imbalance was finally acknowledged in 2001, with the agreed allocation of National funding to improve wards and conditions for psychiatric inpatients, with an emphasis on the provision of comprehensive, effective and quality care within a supportive therapeutic environment (DOH, 2001). 
The value and contribution of mental health service users has also seen a crucial paradigm shift (Tait \& Lester, 2005) in recognition of the importance of the individual clients and their lived experienced (Lim, 2005, Trivedi, 1999). Greater emphasis has been placed on the engagement of service users and the promotion of personal recovery (Glover, 2005). The UK National policy (DOH, 1999a; DOH, 2000a) further emphasised the need to provide quality care through partnership and consultation with service users and their carers (Crawford et al., 2003). This policy is also reflected in other countries (Lloyd et al.1999b; Rebeiro, 2000) and is central to the profession's code of ethics (College of Occupational Therapists, 2005; Occupational Therapy Australia, 2001).

Despite a national commitment to promote partnerships and collaboration (DOH 1999b; DOH 2000b), progress in engaging and involving service users has unfortunately been slow, inconsistent and often not fully embraced (Allot, Loganathon \& Fulford, 2002). This has been most apparent in the area of acute mental health, where traditionally service users have had limited opportunities to be equal partners in discussion and decision making processes about their own treatment and care (Greenwood et al. 1999). This is due to the narrow view held by some professionals that service users might be too unwell to decide what they need or what is beneficial for them or be incapable of making decisions (Deegan, 1996; Trivedi, 1999).

Within the context of this evolving mental health transition, lies the focus of this research study. The particular Mental Health Trust was committed to ensuring that their delivery of mental health acute services embraced the twin objectives of effective mental health provision and collaboration with service users. This coupled with a desire to involve Trust occupational therapists and service users in the research process, dictated the aims and focus of the research design, method and procedure. Importantly the study aims linked closely with 
the core occupational therapy values of pursuing client-centred practice, promoting empowerment (Blank, 2004; Bryant, Craik \& McKay, 2004), inclusion of service users views (Tait \& Lester 2005; Cowls \& Hales 2005), promoting health and recovery (Glover, 2005; Reberio, 2000;) and collaborative partnerships (Lim, 2005).

\section{LITERATURE REVIEW}

In reviewing the literature on occupational therapy in mental health over the previous ten years in the UK, USA, Canada and Australia, Craik (1998) concluded that there was a serious overall shortage of research in mental health occupational therapy, with existing studies concentrated in dementia, work rehabilitation, community mental health and forensic psychiatry. Crucially there were no reported studies on service users’ views of occupational therapy in acute psychiatric inpatient settings, despite the fact that a notable proportion of occupational therapists worked within this area (Craik, Chacksfield \& Richards, 1998)

However, the important contribution of occupational therapy within acute mental health in delivering quality and effective therapeutic input must not be dismissed. Both the Sainsbury Centre for Mental Health (SCMH) Report (1998) and the Department of Health (2001) document support this perspective. Section 4.4 .8 of the latter document states that 'meaningful activity should be determined within an individual's care plan negotiated with service users and that occupational therapists have specific expertise in assisting in this care planning and in the determination and facilitation of a range of appropriate activity inputs on to the ward'.

An examination of existing literature, however, highlights only one study by Di Bona (2004) that examines service user perspectives and satisfaction of occupational therapy provision 
within acute mental health. In the study, 69(68 \%) of acute patients completed a satisfaction questionnaire. The findings indicated that patients had positive views towards occupational therapy staff, a desire for more occupational therapy and the majority responded that the interventions they received were both useful and enjoyable. The group activities rated most enjoyable were, Baking, Gym and Lunch Cookery, whilst Lunch Cookery, Gym, Ward-based exercise and Pottery were rated as most useful. A total of 20(29\%) of patients were engaged in individual occupational therapy sessions and 13(65\%) of these, considered the individual sessions as useful.

Exploring occupational therapy input in three wards in North England, Parkinson (1999) obtained the views of nurses towards ‘open-door’ groups as opposed to formal groups for acutely ill inpatients. The focus of these 'open-groups' was to create increased opportunities for patients to engage in occupational therapy and to involve nursing staff in supporting their engagement. Thirty nurses and nursing assistants were interviewed using a semi-structured questionnaire. The results suggested that staff were better informed and more supportive of the occupational therapy interventions provided, and that service users were more satisfied with less structured and informal groups and that overall group attendance improved. However, this study neglects the views of the patients themselves.

Baker \& McKay (2001) in their study, used a postal questionnaire to survey occupational therapists in medium secure inpatients unit in England ascertaining their views of the needs of female clients. Forty-five therapists (73\%) responded and reported that environmental issues, access to meaningful intervention, gender sensitive care and relationships as important. Although the findings refer to women in secure settings there are implications here 
for other inpatient environments. However the limitation of this study once again was that it surveyed therapists rather than the women themselves.

Greenwood et al.(1999) measured patient satisfaction and its relationship with patient characteristics and their ward experiences, through a survey of 433 inpatients in a South West London NHS Trust. Although over three quarters of those who completed the questionnaire were satisfied, two thirds reported adverse events occurring during their admission. Those who were more dissatisfied with their admission were female patients, younger patients and those detained under the Mental Health Act.

In another study within the same NHS Trust, Greenwood, Hussain, Burns and Raphael (2000) used semi-structured interviews with 14 Asian inpatients and 10 carers. The patients reported boredom, lack of activities during admission, communication problems, lack of understanding on the part of professional staff and indirect racism as part of their inpatient experience and as areas of concern. In a qualitative study, Secker \& Harding (2002) using semi-structured interviews explored the inpatient experiences of 26 service users from African and African Caribbean origins in South East London and obtained similar opinions. Participants indicated that loss of control, experience of overt and implicit racism, unhelpful relationship with some professional staff and lack of activities as negative factors.

In a small qualitative study of 12 acute inpatients, Haley \& McKay (2004) used semistructured interviews to obtain participants views of the benefits of baking. Participants valued being involved in a productive and meaningful occupation, which they considered improved their concentration and confidence. They also appreciated the welcoming and therapeutic environment of the baking sessions. Although most participants understood the 
reasons for their engagement in occupational therapy, they however felt powerless to make changes to their treatment programme.

Within the area of service user involvement and the recovery movement, the majority of available literature consisted of reviews of existing literature (Allot et al., 2002; Tait \& Lester, 2005), opinion pieces (Glover 2005), service user personal narratives (Trivedi 1999; Deegan 1996) and research studies (Crawford et al., 2003; Trivedi \& Wykes, 2002;).

Tait \& Lester (2005), in a review of the existing literature around user involvement, highlights and compares the difference in terminology used to described mental health service users through time. Beginning with the historical perspective of a passive patient, to that of a 'survivor' with positive images of people in distress who have acquired the strength to survive the mental health system, to one of an active consumer with choice and power. This perspective is also supported by Allot et al. (2002), who similarly highlights the paradigm shift and how the focus on empowering the individual requires a conscious decision to redress the balance of power between the professional and the individual client.

Both Trivedi \& Wykes (2002) and Glover (2005), highlight the issue of power dynamic and insecurity that professionals may feel in handing over power and decision making to the service users. Allot et al. (2002) and Glover (2005), further highlights the commitment needed from mental health services towards promoting recovery that is not rooted in normalisation but focused on helping the individual to achieve their own personal recovery. Glover argues the need for services to move towards a recovery based orientation rather than be rooted in maintenance, control and containment. 
Deegan (1996) and Trivedi (1999), also warn against the dangers of further pathologising the individual client and how mental health services have traditionally invalidated the individual identity and experiences of service users. They maintained that without promoting a positive self identity which is essential for the mental well-being of the individual, mental health services are guilty of doing more harm, and restricting the recovery of the individual client.

In one of the few research studies on user involvement, Crawford et al. (2003), in a crosssectional postal survey of user groups and providers of psychiatric services throughout Greater London, received a response rate of 29 (48\%)user groups and 17(94\%) from service providers. On the issue of local NHS Trust commitment to user involvement, of the 25 out of 29 users groups that responded, only 6(21\%) were satisfied, 3 (10\%) were dissatisfied and worryingly 8 (28\%) were extremely dissatisfied. Service providers also identified different ways and methods in which they tried to actively engage service users in the planning and delivery of services. These included ongoing relationships with service user groups, financial support, office and meeting rooms for user groups, having representatives on Trust planning and service development meetings. Crucially, both service providers and user groups agreed about some of the key barriers to greater user involvement. These include how representative the service user groups were of those clients who they purported to represent, especially in terms of minority groups; the attitude of managers and also staff resistance to engaging service users, highlighting the importance of staff education, attitudinal change and organisational commitment.

Many of these studies have been undertaken in London suggesting that London initiatives might be responsible (King’s Fund, 2003; Lim, 2003). However, the lack of research into 
occupational therapy in acute psychiatric inpatient settings is noteworthy with few studies attempting to ascertain the patients perspectives, reinforcing the critical opinions of Wright \& Rowe (2005) and Atwal \& Caldwell (2005), that the occupational therapy profession has failed to fully embrace the service user agenda.

These finding prompted this study, which aimed to:-

1) Ascertain In-patients' perspectives of occupational therapy provision within acute mental health.

2) Involve service users and Trust occupational therapists in the research process.

\section{METHOD}

This study was the result of a partnership between South West London and St George's Mental Health NHS Trust and Brunel University, which aimed to involve practitioners in research. The Trust provides mental health services for a population of just over one million people. At the time of the study the Trust employed around 150 occupational therapy staff and had 10 acute wards. The occupational therapists working in these ten acute wards acted as a reference group for the study while ten community-based occupational therapists assisted with the recruitment of participants and data collection.

As the principal aim of the study was to obtain the opinions of inpatients, local service user groups were consulted at the beginning of the study and users were involved in its design, in recruiting participants and in data collection. For clarity the term service user is employed for the users who recruited the participants and collected data and inpatient is used for the participants themselves. 


\section{Design}

A self report, semi-structured questionnaire was designed to ascertain the perspectives of inpatients about occupational therapy. Existing standardised and non-standardised satisfaction questionnaires were examined for suitability and the two most appropriate, were presented by the first author to the service user groups and the inpatient occupational therapy reference group who felt that neither questionnaire was suitable. Therefore, a new self-report questionnaire was designed, taking into account their views. Following further consultation with, and recommendations from, both groups, a final questionnaire was agreed with 21 questions obtaining basic demographic information and opinion on occupational therapy. Most questions had yes/no/don't know options or a simple Likert scale and some questions solicited further qualitative comments. This penultimate questionnaire was piloted on three service user representatives, who offered valuable feedback, which was incorporated into final research questionnaire.

\section{Ethical approval}

The study was conducted in 2003 prior to the introduction in March 2004 of the New Standard Procedures for Research Ethics Committees. The Trust Research Committee advised that approval for the study would be through the Trust Audit Committee and they subsequently granted approval. The inclusion and exclusion criteria, recruitment of participants, methods of obtaining informed consent and arrangements for distributing the questionnaires were all designed to protect potentially vulnerable inpatients.

\section{Participants}

The participants were inpatients resident at the time of the study in the ten acute wards located at four sites in the Trust. The inclusion criteria were that patients were mentally 
stable, not floridly psychotic and that they had been resident on a ward for at least seven days ensuring that they had the opportunity to participate in occupational therapy during their current admission. Participants in the study were provided with refreshments.

Participants were recruited by ten pairs of people, one pair being allocated to each of the ten acute wards. Ten service users from the local service user groups were paired with ten occupational therapists employed by the Trust in community settings who did not have current clinical contact with inpatients on the wards where data were to be collected. Care was taken to ensure that service users did not return to a ward where they had previously been an inpatient. The ten service users and ten occupational therapists attended a two hour training session provided by the first author to develop their skills to recruit the inpatients and to offer them assistance with completion of the questionnaire if required. The service users were paid the standard Trust fee for their contribution to the study.

\section{Procedure}

Ward managers in the ten wards were notified about the study and informed their inpatients about it. Each ward manager provided the pair of researchers assigned to their ward with a list of inpatients who met the inclusion criteria. Data was collected during a two-week period with each research pair visiting their allocated ward on one day to recruit participants and collect data. Potential participants were approached by the research pair to establish their willingness to contribute to the study. They were given an information sheet which assured their anonymity, that the information they provided would be confidential, that they could withdraw at any time without giving a reason and that their participation would not influence any future care. Those in patients who were willing to participate were then given a consent 
form and when this was completed they were given the self-report questionnaire to complete. The questionnaires were then returned to the research pair.

\section{Data analysis}

The quantitative data were analysed by the Statistical Package for Social Sciences (SPSS) version 10 using a non-parametric test, Spearman’s Rank Correlation Analysis to determine the correlation between the variables. A correlation co-efficient figure towards -1 indicated a negative correlation and a correlation co-efficient figure towards +1 indicated a positive correlation between the variables. A p-value of less than 0.05 indicated that the correlation was statistically significant. The qualitative responses to the open questions were analysed by content analysis, through a process of theme coding. The emerging themes that arose were highlighted and subsequent responses and perspectives catalogued into the respective themes for future content analysis (Bowling, 2002).

\section{RESULTS}

\section{Demographic Data}

A total of 224 inpatients fulfilled the criteria of the study and 64/224 (28.6\%) participated. The response rate for the 10 wards varied from 12(60\%) in ward 1 to 2 (8\%) in ward 10 as illustrated in Table 1.

\section{Insert Table 1 here}

Of the 64 participants 37 (57.8\%) were female and 27 (42.2\%) were male; the majority of participants 39 (60.9\%) reported their martial status as single, twelve (18.8\%) as married and nine (14\%) as divorced or separated. The mean age was 40.4 years, range 18-77 years with four participants over 65 years the cut-off point for adult services. The largest proportion of 
participants was White British 34(53.1\%), followed by Black African Caribbean 5 (7.8\%). Two thirds of the participants had been inpatients for 2 months or less. Two participants had a current inpatient stay of up to 12 months.

\section{Involvement in occupational therapy}

Participants reported on their contact and experience of occupational therapy whilst on their ward. As indicated in Table 2, 53(82.8\%) of participants had met an occupational therapist, with two thirds provided with an explanation of the purpose of occupational therapy. Three quarters of those engaged in occupational therapy also considered it helpful. There was a highly significant positive correlation between meeting an occupational therapist and having the purpose of occupational therapy explained with the p-value at $(0.01)$ and the co-efficient was (0.627). A highly significant and positive correlation was also found between having the purpose of occupational therapy explained and considering that it would be helpful where the p-value was (0.02) and the co-efficient was (0.259).

Two thirds of participants had been fully involved or involved in deciding their occupational therapy programme with 27(42.2\%) indicating they were involved or fully involved in agreeing individual intervention goals. Just over half 33(51.5\%) participants were provided choice about individual intervention and 45(70.3\%) with occupational therapy groups. There was no statically significance (P-value 0.355 ) between meeting an occupational therapist and being involved in agreeing individual goals, and there was no positive correlation at (0.048). However, the correlation between, agreeing and deciding on individual goals and having choice in their individual occupational therapy intervention produced a highly significant pvalue (0.016) and moderate positive correlation figure of (0.299). 
From a list of 16 activities provided on the wards, participants as indicated in Table 3, ranked arts and crafts, community meetings, relaxation groups, music groups with cookery groups and sports as most popular. Participants also rated cookery groups and sports \& gym as most helpful and beneficial. In explaining helpful activities, participants indicated that the cookery group helped them acquire and practise skills that were most relevant following their discharged home. Those participants who chose sports \& gym mentioned that keeping fit and active, reducing stress and physical fitness as reasons for finding this group beneficial.

\section{Views on Participating in Occupational Therapy}

More than 50\% of participants reported that engaging in occupational therapy had helped their functioning in daily life, indicating that it had assisted them to improve their concentration, focus their minds, structure their day, provide opportunities to socialise and interact with others, promote their creative expression and enhance their self-confidence. Just over half 34(53.1\%) felt that occupational therapy improved their confidence, mentioning the opportunity to learn and practise new skills, the supportive group environment and socialising with other people in groups as key factors. Again just over half 35(54.7\%) of the participants commented that occupational therapy met their needs helping them to structure their time, relax and relieve boredom. However, 20(31.3\%) felt that occupational therapy had not met their needs, indicating the relevance, amount of input and choice available being insufficient. Three quarters of the participants highlighted that occupational therapy was important, noting daily structure, breaks from the ward environment, learning new skills and having space for creative expression as helping them improve their confidence. It also provided enjoyment and aided their recovery. Just under half of the participants 29(45.3\%) also felt that the occupational therapist had shown some 
awareness and sensitivity to their cultural, religious and ethnic needs in relation to planning their care, visiting places of religious importance and preparing food from different cultures (Table 4).

There was a moderately positive correlation, but not statistically significant correlation between agreement of individual goals and perceiving occupational therapy as improving function and confidence. However, a highly significant and strong positive correlation was indicated between 'helped function' and 'improved confidence' where the p-value was (0.01) and the co-efficient value was 0.684 . A similar outcome was found in the correlation between occupational therapy meeting needs and improving function, which was highly significant p value (0.01) and produced a strong positive correlation value of (0.705).

\section{Satisfaction with Occupational Therapy}

Over half (36/64) of participants were satisfied or very satisfied with the amount of occupational therapy they received, while 23/64 (35.9\%) were dissatisfied stating they wanted more choice, opportunity and wanted it to be more readily available.

As indicated in Table 5 over two thirds of the participants judged that occupational therapy had improved the quality of their admission, mentioning that it helped with their treatment, made them feel more relaxed, added diversity to daily routine, improved their confidence, self-esteem, manage their stress and anxiety and provided something to do. Similarly, just over half, 34(53.1\%) felt that occupational therapy had helped them to deal more effectively with their difficulties. Almost half of the participants 31(48.4\%) also considered that occupational therapy was readily available, however, 27(42.4\%) wanted occupational therapy in the evenings and at weekends and more individual rather than group sessions. 
Two thirds of participants also indicated they would request to see an occupational therapist again if they needed help in the future and almost $80 \%$ of the participants would recommend their friends to see an occupational therapist if they needed help.

A highly statistically significant p value (0.002) and moderately positive correlation (0.349) was also found between meeting needs and requesting to see an occupational therapist again in the future. The correlation between occupational therapy meeting needs and improving the quality of hospital stay was highly significant (0.01) and produced a strong positive correlation of (0.632).

\section{DISCUSSION}

The overall response rate was low at $28.6 \%$, but this was not unexpected given the nature of the study and its setting. Caution is therefore required in interpreting these findings, however in view of the lack of research into users' views of occupational therapy in acute mental health, these results are beneficial in examining the perspectives and reflections of the inpatients participants who took part.

Although each research pair of service user and community occupational therapist attended the training session to ensure that data collection was conducted in a similar way, there were variations in the response rate between wards. This may have been due to a disparity in data collection or ward variations in terms of occupational therapy input. In wards with a higher response rate, there was correspondingly more occupational therapy input. In contrast, the only ward without an allocated occupational therapist had the lowest response rate. Therefore the lower response rate could indicate the dissatisfaction of inpatients participants 
or their lack of understanding of occupational therapy due to limited contact and thereby curbing involvement in the study. These finding reflect the concerns of the Sainsbury Centre for Mental Health (1998, 2002) and the Department of Health (1999b, 2001), which highlights issues of disparity of provision and lack of knowledge and understanding, limiting involvement and engagement on the part of service users in their own care (Reberio 2000; Lim 2005).

\section{Involvement in occupational therapy}

In the study, over 53(82\%) of respondents had met an occupational therapist, whilst 50(78\%), had engaged in occupational therapy. However only 43(67\%) had the purpose of occupational therapy explained and 48(75\%) mentioned finding it helpful. Importantly a highly significant positive correlation was found between having an explanation of occupational therapy and finding it helpful. This also highlights the importance that these factors have in influencing engagement, as similarly highlighted by Di Bona (2004) study where patients' attendance and engagement in occupational therapy improved when they understood they were working through their problems and not merely filling in time.

Although two thirds of participants were involved in deciding on their own occupational therapy group programme, around half were however not involved in agreeing their individual goals and did not have choice about individual interventions. This reflects the views of participants in the Haley \& McKay (2004), where participants found occupational therapy valuable but felt powerless to make changes to their programme. Similarly, Blank (2004), in a study of seven clients within community mental health, noted a lack of individual approach, communication and knowledge on the part of the occupational therapist, as barriers to partnership working. It could be also be concluded that negative therapist/staff attitude and 
lack of commitment as highlighted by (Crawford et al., (2003); Cowls \& Hales (2005);

Wright \& Rowe (2005) are barriers to greater involvement and engagement of users.

However it maybe that the therapists had limited the choices and decision making opportunities for benevolent reasons, judging the inpatient to be too acutely ill or in too stressful a setting to cope with option selection and decision making. This would confirm the concerns indicated by (Deegan (1996) and Trevidi (1999) of professionals basing their decision on their own perception rather than the actual capabilities of the individual client. The lack of involvement and engagement of patients also represents a failure to meet both professional standards (COT, 2005) which emphasises client centred practice and engagement of clients throughout the therapeutic process and Department of Health (2001) guidance that all meaningful activity should be determined in consultation with patients. The positive correlation between having the purpose of occupational therapy explained to inpatients and their rating of the input as helpful, is a clear incentive for therapists to fully engage clients in their intervention.

In the area of choice to attend therapeutic groups, 45(70.3\%) responded that they were provided this opportunity. Participants rated cookery groups and sport and gym sessions as most beneficial and interestingly these findings corresponded with those in the study by Di Bona (2004), which similarly indicated sports, gym and cookery as rated by respondents as both useful and enjoyable. The positive comments made in terms of engagement in meaningful occupations, reinforced those found in previous studies (Greenwood et al., 1999; Parkinson 1999; Haley \& McKay, 2004) which highlighted the importance of occupational therapy being relevant, appropriate and focused on fulfilling the specific needs of the individuals. 


\section{Satisfaction with occupational therapy}

Over half the participants reported that occupational therapy helped them to function better in their daily life, met their needs and that they were more confident about their own skills and abilities. These views were similarly supported by respondents in the studies by Di Bona (2004) and Parkinson (1999). Participants’ positive comments provided insight and strategies for promoting the benefits and relevance of occupational therapy to those who have little knowledge or experience of the profession. However about a third of respondents indicated occupational therapy had not fully met their needs, citing the lack of variety and relevance of available interventions as an issue. Some participants also wanted occupational therapy to be available both evenings and at weekends as similarly indicated in the studies by (Haley \& McKay 2004) and Di Bona (2004) where a lack of available therapeutic activity and boredom is more prevalent.

The perceived lack of flexibility and choice, coupled with the need to be referred, in order to participate in groups, also raised some dissatisfaction. Parkinson (1999) overcame this issue in her study by implementing informal referral free occupational therapy groups on the ward, which resulted in increased patient uptake of occupational therapy almost doubling. Allot et al. (2002) similarly supports the need to promoted real choice in terms of providing a diverse selection of interventions and opportunities, intertwined with collaboration in planning and decision makings as raised by other authors (Tait \& Lester, 2005; Di Bona, 2004; Trivedi \& Wkyes, 2002). This further supports the view of Deegan (1996), Reberio (2000) and Glover (2005) for the need for mental health services to be focused on promoting the recovery of the client through enhancing individual choice and power. 
Opinion was divided about awareness and sensitivity of occupational therapists to the cultural, religious and ethnic needs of patients. Concerns were expressed that occupational therapy staff and programmes provided were not sufficiently sensitive to diverse needs and requirements. Although these views were not as negative as those reported by Greenwood et al (1999, 2000) and Secker and Harding (2002), they reinforced the importance of therapists being aware of communication and interaction patterns between staff and patients, highlighting the role of collaboration and partnership working indicated by Trivedi (1999) and Tait \& Lester (2005) in ensuring provision of sensitive, appropriate and quality care.

There was also a highly significant and strong positive correlation between the occupational therapy programme meeting the needs of inpatients and their corresponding views that it improved their personal functioning, satisfaction and quality of stay on the ward as similarly indicated in the study by Di Bona (2004). They were therefore also more likely to agree to see an occupational therapist in the future, when encountered with similar difficulties. Crucially, participants mentioned they would recommend their friends to see an occupational therapist, if they were experiencing similar difficulties, strengthening the value of occupational therapy to these inpatients.

While the difficulties of obtaining the views of users have been acknowledged, especially in relation to vulnerable groups like older people, the involvement of users in the design and implement of satisfaction surveys has been advocated (Atwal \& Caldwell, 2005). In this study the involvement of service users in the design and review of the questionnaire and especially in the recruitment of participants and data collection was a particular strength and adds weight to the findings. This supported the view by Trivedi \& Wkyes (2002) and Bryant et al. (2004) and Lim (2005) that there is a need to involve service users in all aspect of 
deciding, planning and evaluating their own care. An evaluation of the perspectives and experiences of both professionals and service users in undertaking joint training, recruitment, data collection and collaborative research would have enhanced the quality of the study and provided future ventures in joint working.

\section{CONCLUSIONS}

The study achieved the aim of ascertaining inpatient perspectives of occupational therapy provision in acute mental health, highlighting not only the satisfaction levels and views of respondents, but also raising additional areas of potential research, including the quantity and distribution of occupational therapy input likely to be most effective on acute wards. It also indicated participants had more choice with group than individual intervention and they desired more individual sessions. The provision of additional information on both individual and group intervention would also benefit participants in decision making and choice selection. Occupational therapists need to ensure they consult with inpatients in deciding on their individual goals and targets and providing more individual interventions aimed at working through individual difficulties. Further research exploring the relative benefits for inpatients engaging in group versus individual intervention is also indicated. Further the issue of evening and weekend provision of occupational therapy, must also be fully considered.

Groups with an occupational focus which were meaningful and relevant were seen as most beneficial to these inpatients, adding to the growing available evidence in acute mental health (Haley \& McKay, 2004) and in the community (Chugg \& Craik, 2002; Mee, Sumsion and Craik, 2004; Pierris \& Craik 2004) that occupational based interventions work. In particular, the judgement that cookery and sports and gym were the most beneficial occupations reinforces the findings of Di Bona (2004) and is a powerful signal to occupational therapists 
to include these occupations in their intervention programmes for people with acute mental health problems. Further research into the reasons for its effectiveness are indicated. These findings add further weight to the focus within the profession to return to an occupational focus in intervention and reinforces the provision of these groups on the inpatient wards.

The study also fulfilled the second aim of providing the unique opportunity for service users and occupational therapists to be involved in the research process and collaboratively undertake the design, review, recruitment and data collection for the study. The experience of both groups in joint working, consultation and involvement in the research process is another potential area for further research and evaluation in the interest of promoting future partnership and collaboration. 


\section{ACKNOWLEDGEMENTS}

Thanks are extended to the inpatients who participated in the study; the service user groups who contributed to its design; the service users and community occupational therapists who recruited the participants and collected the data; the inpatient occupational therapy staff who formed the reference group and Mary Morley, Director of Occupational Therapy at the Trust. 


\section{REFERENCES}

Allot, P., Loganathan, L. \& Fulford, K. (2002) Discovering Hope for Recovery from a British Perspective. Canadian Journal of Community Mental Health 21(3) 1-23

Atwal, A. \& Caldwell, K. (2005). Older people: the enigma of satisfaction surveys. Australian Occupational Therapy Journal, 52,10-16.l

Baker, S. \& McKay, E. A. (2001). Occupational Therapists’ Perspectives of the Needs of Women in Medium Secure Units. British Journal of Occupational Therapy, 64(9), 441-448.

Blank, A. (2004). Clients' experience of partnership with occupational therapists in community mental health. British Journal of Occupational Therapy, 67(3), 118-124.

Bowling, A. (2002) Research methods in Health. Open University

Bryant, W., Craik, C. \& McKay, E. A. (2004) Living in a glasshouse.

Canadian Journal Occupational Therapy, 71,282-289.

Chugg, A. \& Craik, C. (2002). Some factors influencing Occupational Engagement for people with Schizophrenia living in the Community. British Journal of Occupational Therapy, 65 (2), $67-74$.

College of Occupational Therapists (2005). Code of Ethics and Professional Conduct for Occupational Therapists. London: College of Occupational Therapists

Cowls, J. \& Hales, S. (2005) It's the activity that counts: What clients value in Pyschoeducational groups. Canadian Journal Occupational Therapy, 72: 176-182

Craik, C. (1998). Occupational Therapy in Mental Health: A Review of the Literature. British Journal of Occupational Therapy, 61(5), 186-192.

Craik, C., Chacksfield, J.D. \& Richards, G. (1998). A Survey of Occupational Therapy Practitioners in Mental Health. British Journal of Occupational Therapy, 61(5), 227-234

Crawford, M.J., Aldridge, T., Bhui, K., Rutter, D., Manley, C., Weaver, T., Tyrer, P., Fulop, N. (2003) User involvement in the planning and delivery of mental health services: a crosssectional survey of service users and providers. Acta Psychiatr Scand 2003: 107:410-414

Deegan P (1996) Recovery as a Journey of the Heart. Psychiatric Rehabilitation Journal 19(3) 92-97.

Department of Health (1999a). National Service Framework for Mental Health. London: $\mathrm{DH}$

Department of Health (1999b). Patient and public Involvement in the New NHS. London: $\mathrm{DH}$ 
Department of Health (2000a). The NHS Plan: A plan for investment, a plan for reform. London: $\mathrm{DH}$

Department of Health (2000b). Working partnerships. Consumers in Research: Third Annual Report London: $\mathrm{DH}$

Department of Health (2001). Mental Health Policy Implementation Guide. London: DH

Di Bona, L. (2004) What do they think of us? A satisfaction survey of users of occupational therapy services in an acute inpatient mental health unit.

Mental Health Occupational Therapy, 9: 77-81

Glover, H. (2005) Recovery based service delivery: are we ready to transform the words into a paradigm shift? Australian e-Journal for the advancement of Mental Health, 4:1-4 Retrieved $22^{\text {nd }}$ June 2006 from www.ausinet.com/journal/vol4iss3/glover.pdf

Greenwood, N., Key, A., Burns, T., Bristow, M. \& Sedgewick, P. (1999). Satisfactions with inpatient psychiatric services. British Journal of Psychiatry, 174, 159-163.

Greenwood, N., Hussain, F., Burns, T. \& Raphael, F. (2000). Asian Inpatient and Carer Views of Mental Health Care. Journal of Mental Health, 9(4), 397-408.

Haley, L. \& McKay, E. A., (2004). 'Baking gives you confidence’: users’ views of engaging in the occupation of baking, British Journal of Occupational Therapy, 67(3), 125-128.

King’s Fund (2003). London’s Mental Health, London: King’s Fund

Lim, K.H. (2003). Report on The King's Fund Mental Health Inquiry. Occupational Therapy News, 11(3), 15.

Lim, K.H. (2005). Partnership, Involvement and Inclusion. Mental Health Occupational Therapy, 10(1), 22-24

Lloyd, C., Kanowski, H. \& Maas, F. (1999). Occupational therapy in mental health: Challenges and opportunities, Occupational Therapy International, 6(2), 110-125.

Lloyd, C., King, R. \& Maas, F. (1999). The Impact of Restructuring Mental Health Services on Occupational Therapy. British Journal of Occupational Therapy, 62(11),507-513 .

Mee, J., Sumsion, T. \& Craik, C. (2004) Mental health clients confirm the value of occupation in building competence and self-identity, British Journal of Occupational Therapy, 67(5), 225-233.

OT Australia (2001) Code of ethics: Australian Association of Occupational Therapists . Retrieved $24^{\text {th }}$ January 2006 from http://www.ausot.com.au/images/OT\%20AUSTRALIA\%20Code\%20of\%20Ethics(2).pdf

Parkinson, S. (1999). Audit of a Group Programme for Inpatients in Acute Mental Health Settings. British Journal of Occupational Therapy, 62(6), 252-256. 
Pierris, Y. \& Craik, C. (2004). Factors supporting and hindering the participation of people with mental health problems in leisure, British Journal of Occupational Therapy, 67(6), 240 247.

Reberio, K. (2000), Client perspectives on occupational therapy practice: are we truly clientcentred? Canadian Journal of Occupational Therapy 67(1), 7-14

Sainsbury Centre for Mental Health (1998). Acute Problems: A survey of Quality Care in Acute Psychiatric Wards. London: Sainsbury Centre for Mental Health

Sainsbury Centre for Mental Health (2002). An Executive Briefing on adult acute inpatient care for people with mental health problems. London: Sainsbury Centre for Mental Health

Secker, J. \& Harding, C. (2002). African and African Caribbean User's Perceptions of Inpatient Services. Journal of Psychiatric and Mental Health Nursing, 9(2), 161-168.

Tait, L. \& Lester, H. (2005) Encouraging user involvement in mental health services. Advances in Psychiatric Treatment 11:168-175

Trivedi, P.(1999) Unanswered questions: A User’s perspective. In Bhui, K. \& Olajide, D. (ed) Mental health service provision: For a multi-cultural society. Saunders London pp 11-20.

Trivedi, P. \& Wykes, T. (2002) From passive subjects to equal partners.

British Journal of Psychiatry 2002 181: 468-472

Wright, C. \& Rowe, N. (2005). Protecting professional identities: service user involvement and occupational therapy. British Journal of Occupational Therapy, 68(1), 45-47. 
Table 1 Response rate by ward

\begin{tabular}{|cccccll|}
\hline Ward & \multicolumn{2}{c}{ Patients } & \multicolumn{2}{c|}{ Respondents } & No \& Grade of Staff & Comments \\
& N & $\begin{array}{c}\text { N } \\
\text { eligible }\end{array}$ & N & $\%$ & & \\
1 & 22 & 20 & 12 & 60.0 & 1 Senior 1 & \\
2 & 11 & 10 & 4 & 40.0 & 1 Basic Grade & \& 2 sessions from CMHT \\
3 & 24 & 23 & 9 & 39.1 & 1 Basic Grade & \& 2 sessions from CMHT \\
4 & 26 & 23 & 8 & 34.8 & 0.5 Tech + 0.6 Senior & \\
& & & & & 1 & \\
5 & 38 & 36 & 11 & 30.6 & 0.5 Tech + 1 Senior 1 & \\
6 & 29 & 27 & 7 & 25.9 & 1Tech + 0.6 Senior 1 & \& input from CMHT \\
7 & 23 & 20 & 4 & 20.0 & 0.5 Tech + 0.45 Senior & \\
& & & & & 1 & \\
8 & 23 & 20 & 4 & 20.0 & 1Tech + 1 Senior 11 & Shared with Ward 9 \\
9 & 23 & 20 & 3 & 15.0 & 1Tech + 1 Senior 11 & Shared with Ward 8 \\
10 & 28 & 25 & 2 & 8.0 & None & \& 2 sessions from CMHT \\
TOTAL & 247 & 224 & 64 & 28.6 & & \\
\hline
\end{tabular}

Table 2 Contact with occupational therapy

\begin{tabular}{|lccccccccc|}
\hline \multicolumn{1}{c}{$\begin{array}{c}\text { Statement about occupational } \\
\text { therapy }\end{array}$} & \multicolumn{2}{c}{ Yes } & \multicolumn{2}{c}{ No } & \multicolumn{2}{c|}{ Not Sure } & \multicolumn{2}{c|}{ Total } \\
& $\mathrm{N}$ & $\%$ & $\mathrm{~N}$ & $\%$ & $\mathrm{~N}$ & $\%$ & $\mathrm{~N}$ & $\%$ \\
Met an occupational therapist & 53 & 82.8 & 10 & 15.6 & 1 & 1.6 & 64 & 100 \\
Offered occupational therapy & 50 & 78.1 & 13 & 20.3 & 1 & 1.6 & 64 & 100 \\
Purpose explained & 43 & 67.2 & 20 & 31.3 & 1 & 1.6 & 64 & 100 \\
Would be helpful & 48 & 75.0 & 15 & 23.4 & 1 & 1.6 & 64 & 100 \\
\hline
\end{tabular}

Table 3 Involvement in activities and groups

\begin{tabular}{|lcccc|}
\hline Activity/Group & \multicolumn{3}{c|}{ Participation } & \multicolumn{2}{c|}{ Helpfulness } \\
& $\mathrm{N}$ & $\%$ & $\mathrm{~N}$ & $\%$ \\
Arts and crafts & 33 & 51.6 & 10 & 30.3 \\
Community Meetings & 26 & 40.6 & 4 & 15.4 \\
Relaxation & 24 & 37.5 & 7 & 29.2 \\
Music group & 16 & 25.0 & 4 & 25.0 \\
Cookery group & 12 & 18.8 & 7 & 58.3 \\
Sports \& gym & 12 & 18.8 & 7 & 58.3 \\
Baking & 9 & 14.1 & 3 & 33.3 \\
Creative writing & 8 & 12.5 & 2 & 25.0 \\
Pottery & 5 & 7.8 & 2 & 40.0 \\
Discharge planning & 5 & 7.8 & 2 & 40.0 \\
Gardening & 3 & 4.7 & 1 & 33.3 \\
Anxiety management & 3 & 4.7 & 0 & 0.0 \\
Vocational group & 3 & 4.7 & 0 & 0.0 \\
Living skills & 3 & 4.7 & 1 & 33.3 \\
Men's group & 2 & 3.1 & 1 & 50.0 \\
Women's group & 0 & 0.0 & 0 & 0.0 \\
\hline
\end{tabular}


Table 4 Views on participating in occupational therapy

\begin{tabular}{|c|c|c|c|c|c|c|c|c|}
\hline \multirow{2}{*}{$\begin{array}{l}\text { Statement about occupational } \\
\text { therapy }\end{array}$} & \multicolumn{2}{|c|}{ Yes } & \multicolumn{2}{|c|}{ No } & \multicolumn{2}{|c|}{ No answer } & \multicolumn{2}{|c|}{ Total } \\
\hline & $\mathrm{N}$ & $\%$ & $\mathrm{~N}$ & $\%$ & $\mathrm{~N}$ & $\%$ & $\mathrm{~N}$ & $\%$ \\
\hline Helped with daily functioning & 36 & 56.3 & 21 & 32.8 & 7 & 10.9 & 64 & 100 \\
\hline $\begin{array}{l}\text { Improved confidence in skills and } \\
\text { abilities }\end{array}$ & 34 & 53.1 & 23 & 35.9 & 7 & 10.9 & 64 & 100 \\
\hline Met my needs & 35 & 54.7 & 20 & 31.3 & 9 & 14.1 & 64 & 100 \\
\hline $\begin{array}{l}\text { Aware of cultural, religious \& ethnic } \\
\text { needs }\end{array}$ & 29 & 45.3 & 23 & 35.9 & 12 & 18.8 & 64 & 100 \\
\hline Important to participate & 48 & 75.0 & 7 & 10.9 & 9 & 14.1 & 64 & 100 \\
\hline
\end{tabular}

Table 5 Benefits and Satisfaction with Occupational Therapy

\begin{tabular}{|lccccccccc|}
\hline $\begin{array}{l}\text { Statement about occupational } \\
\text { therapy }\end{array}$ & \multicolumn{2}{c}{ Yes } & \multicolumn{3}{c}{ No } & \multicolumn{3}{c|}{ No answer } & \multicolumn{3}{c|}{ Total } \\
& $\mathrm{N}$ & $\%$ & $\mathrm{~N}$ & $\%$ & $\mathrm{~N}$ & $\%$ & $\mathrm{~N}$ & $\%$ \\
Improved quality of stay in hospital & 43 & 67.2 & 13 & 20.3 & 8 & 12.5 & 64 & 100 \\
Helped effectively manage difficulties & 34 & 53.1 & 23 & 35.9 & 7 & 10.9 & 64 & 100 \\
Available when wanted & 31 & 48.4 & 27 & 42.2 & 6 & 9.4 & 64 & 100 \\
Would ask again if help was needed & 44 & 68.8 & 14 & 21.9 & 6 & 9.4 & 64 & 100 \\
Would recommend to a friend & 51 & 79.7 & 6 & 9.4 & 7 & 10.9 & 64 & 100 \\
\hline
\end{tabular}

